\title{
Infectious Mononucleosis Complicated With Idiopathic Thrombocytopenic Purpura: A Case Report and Literature Review
}

\section{Yong Ren ( $\sim$ rybest@126.com )}

Hubei key laboratory of Central Nervous System Tumor Occurrence and Intervention, Central Theater General Hospital, Wuhan, China, 627 Wuluoluo Road, Wuchang District, Wuhan City 430060, Hunan Province, China

\section{Qiong Wang}

Hubei key laboratory of Central Nervous System Tumor Occurrence and Intervention, Central Theater General Hospital, Wuhan, China, 627 Wuluoluo Road, Wuchang District, Wuhan City 430060, Hunan Province, China

\section{Qiang Liu}

Department of special examination, No. 927 Hospital of PLA, Joint Logistics Support Force, 3 Yushui Road, Simao District, Puer City 665000, Yunnan Province, China Jinsheng Zhang

Hubei key laboratory of Central Nervous System Tumor Occurrence and Intervention, Central Theater General Hospital, Wuhan, China, 627 Wuluoluo Road, Wuchang District, Wuhan City 430060, Hunan Province, China

\section{Case Report}

Keywords: infectious mononucleosis, idiopathic thrombocytopenic purpura, Epstein-Barr virus

Posted Date: August 4th, 2020

DOI: https://doi.org/10.21203/rs.3.rs-49183/v1

License: (a) (i) This work is licensed under a Creative Commons Attribution 4.0 International License. Read Full License 


\section{Abstract}

\section{Background:}

Epstein-Barr virus (EBV) is the cause of infectious mononucleosis (IM), a self-limited lymphoproliferative disorder among patients. EBV usually infects B-lymphocytes rather than T-lymphocytes. The clinicopathologic features of the idiopathic thrombocytopenic purpura (ITP) patients complicated with EBV-positive IM have been rarely described.

\section{Case presentation:}

We describe a case of a 19-year-old man complained with epistaxis and thrombocytopenia for one year, who was admitted to hospital for high grade fever after catching a cold. A lot of petechiae were found on the skin of both lower limbs and both hands during physical examination. Multiple enlarged lymph nodes could be touched in both sides of the neck. Ultrasound examination showed abnormal lymph nodes enlargement on both sides of the neck and supraclavicular area, and a strong echo mass was found in the liver. Serological tests for EBV revealed high level of IgM and IgG antibodies against viral capsid antigen (VCA), virus DNA quantitative $<1000 \mathrm{UI} / \mathrm{mL}$. CD8-positive cytotoxic T cells accounted for up to 92.94\% by flow cytometry. T cells were positive for CD38, CD57 and HLA-DR marker. Bone marrow cytology showed that the proportion of lymphocytes had increased considerably, and the rate of abnormal lymphocyte was as high as $29.5 \%$. EBV virus encoded RNA was demonstrated in lymph node biopsy by in-situ hybridization (ISH) analysis. Immunohistochemically, there were more CD8-positive cells than CD4-positive cells in lymph node biopsy. The expression of CD7 was missing. CD99 was diffuse positive. The MIB-1/ki-67 labeling index was about 70\%. EBER in situ hybridization revealed positive signals located in the nucleus. The patient was diagnosed as Infectious mononucleosis complicated with idiopathic thrombocytopenic purpura. The patient was hospitalized and discharged after recovery.

\section{Conclusions:}

ITP patients complicated with EBV-positive IM have been rarely reported in the literature. Comprehensive understanding of its clinicopathological features will help diagnose of this disease.

\section{Background}

Infectious mononucleosis is a self-limited disease caused by Epstein-Barr virus infection. Primary infection usually occurs among children and adolescents. The most common symptoms of acute EBV infection are fever, lymphadenopathy, tonsillitis and fatigue [1]. Epstein-Barr virus is generally considered to only infect B cells [2,3], that is, to activate lymphocytoblast cells and immunoblast cells. However, some scholars have found that EBV can also infect T cells, and immunotoxins tests revealed that EBV could infect CD4-positive helper/inducer T cells [4]. Here we present an unusual case of ITP patient complicated with IM which was caused by EBV infection of T cells. Previously reported cases were reviewed. 


\section{Case Presentation}

A 19-year-old man suffered from ITP for one year. He had high fever after catching cold with the highest temperature reaching $39^{\circ} \mathrm{C}$ three days ago, accompanied by right nosebleed. The patient had no pharynx, night sweats, chest tightness, asthma, cough, phlegm, abdominal pain, diarrhea, black stool, hematuria or other discomfort. There were many petechiae on the skin of both lower limbs and both hands (figure 1, 2). Multiple enlarged lymph nodes could be touched in both sides of the neck. From ultrasound examination, enlarged lymph nodes with abnormal structure were identified on both sides of the neck and supraclavicular area. Lymph nodes were checked in the axilla and groin of both sides without obvious abnormal structure. A strong echo mass measuring $0.6 \times 0.4 \mathrm{~cm}$ could be found in the liver. Laboratory tests showed that red blood cells, $4.8 \times 10^{12} / \mathrm{L}\left(4.3-5.8 \times 10^{12} / \mathrm{L}\right)$; white blood cells, $11.4 \times 10^{9} / \mathrm{L}(4.0-$ $\left.10 \times 10^{9} / \mathrm{L}\right)$; platelets, $13 \times 10^{9} / \mathrm{L}\left(125-300 \times 10^{9} / \mathrm{L}\right)$. Serological tests showed high level of $\mathrm{EBV}$, which revealed IgM and IgG antibodies against VCA. Virus DNA quantitative $<1000 \mathrm{UI} / \mathrm{mL}$. Flow cytometry analysis revealed a $92.94 \%$ population of CD8-positive cytotoxic T cells in peripheral blood, CD4/CD8 $=0.07$, and T cells were positive for CD38, CD57 and HLA-DR marker. Bone marrow cytology showed that the proportion of lymphocytes had remarkably increased, and the rate of abnormal lymphocyte was as high as $29.5 \%$. In-situ hybridization (ISH) analysis showed EBV virus-encoded RNA was positive in Lymph node biopsy.

Histologically, hematoxylin and eosin stain revealed partial thickening of lymph node capsule. Hemorrhage and lymphocyte infiltration were observed in the tissue outside the capsule. The subcapsular sinus was dilated with infiltration of lymphocytes and plasma cells. Some arteriole wall thickened and lumen dilated in cortical area. A few follicular germinal centers were enlarged, irregular in shape, and the polarity disappeared (figure3). Some follicles were crowded and the interfollicular area disappeared. Paracortical area expanded with mixed lymphocytes of different sizes. Activated lymphocytoblast cells, immunoblast cells and plasma cells were observed, while few mitosis and a lot of endothelial veins were observed.

In the immunohistochemistry study, there were more CD8-positive cells than CD4-positive cells in lymph node biopsy. CD21 highlighted the irregular follicular dendritic meshwork. The expression of CD7 was negative. CD 99 was diffusely positive. The MIB-1/ki-67 labeling index was approximately $70 \%$. EBER-ISH demonstrated that EBER positive signals located in the nucleus, and the maximum number of positive cells was approximately 60/HPF. By using double staining in-situ hybridization with immunostaining against CD20, the CD20-positive cells were EBER negative cells, as well as CD3-positive cells were EBER positive cells. Based on the finding above, the patient was diagnosed as ITP complicated with EBVpositive IM. The patient was hospitalized and received treatment.

\section{Discussion}

Infectious mononucleosis is a self-limited disease [5], it can occur in both men and women, mainly in children and young adults. The symptoms are fever, pharyngeal pain, fatigue and lymphadenectasis. A 
few patients have swelling in tonsils, spleen and liver [6, 7]. "Abnormal lymphocytes" can be found in peripheral blood, they are usually identified as CD8-positive T cells [8]. Epstein-Barr virus serum antibody increases in peripheral blood. The prognosis is usually favorable. Histologically, the capsule of lymph nodes are thin [9]. In this case, the capsule thickened in the focal area, and there was lymphocyte infiltration outside the capsule. We speculate that the patient may had experienced ITP symptoms such as hemorrhage in the lymph node capsule, which might be a reaction of the IM patient to bleeding.

EBV infects $B$ cells with C3d complement receptor (CD21), and EBV infection induces CD8-positive cytotoxic $T$ cells against $B$ cells. These activated $T$ cells can be detected in patients' peripheral blood. The immunophenotype of our case showed that the lymphocytes were mainly CD8-positive T cells in the Paracortical enlargement, which expressing CD30, EBER and CD3. Studies have shown that mature T cells express low levels of CD21, but EBV infected T cells are rare [10]. This case showed that EBV infected CD3 and CD8 positive T cells. Maybe there are some unknown receptors in the CD3 and CD8 positive T cells which led to the direct EBV infection in the ITP patients. This conclusion needs more cases.

Both IM and systemic EBV + T-cell lymphoma of childhood are diseases that present with scattered, atypical, EBV-positive cells and, because of these similarities, these entities may be mistaken for one another. The latter distinguishes from IM by the presence of poor clinical prognosis, usually within a few days to a few weeks, rapid disease progression and even death can occur. Then we can also exclude T/NK cell chronic active EBV infection (caebv-t /NK), whose diagnostic criteria is fever lasting for at least 3 months.

\section{Conclusions}

In summary, we described a rare case of ITP combined with IM. The case showed that EBV infected CD3 and CD8 positive T cells. The patient was treated with drugs (omeprazole enteric capsule and prednisone) after discharged. During the followed two years he was normal. Further question needs to be studied: the relationship between CD8 and CD 99 positive T cells in IM patients. The case of ITP combined with IM has rarely been reported. Infectious mononucleosis should be taken into consideration when ITP patient has fever and there is lymph node enlargement, and pathological biopsy should be performed. There is still a lack of large-scale data on how to make effective diagnosis and proper treatment. This report makes a preliminary exploration.

\section{List Of Abbreviations}

EBV: Epstein-Barr virus; IM: infectious mononucleosis; ITP: idiopathic thrombocytopenic purpura; VCA: viral capsid antigen; HLA-DR: Human Leukocyte Antigen-DR; ISH: in-situ hybridization; EBER: Epstein-Barr virus-encoded small RNA; HPF: high power field.

\section{Declarations}




\section{Ethics approval and consent to participate}

This case study was approved by the Institutional Ethics Committee of Central theater of war general hospital, Wuhan, China.

\section{Consent for publication}

Written informed consent was obtained from the patient for the publication of this case report and any accompanying images.

\section{Availability of data and materials}

All data analyzed during this case are included within the article.

\section{Competing interests}

The authors declare that they have no competing interests.

\section{Funding}

Not applicable.

\section{Authors' contributions}

WQ collected the clinical data and drafted the manuscript. ZJS, WQ, LQ and RY made the pathological diagnosis. LQ and RY made revision to the final manuscript and provided the funding support. All authors read and approved the final manuscript.

\section{Acknowledgments}

Not applicable.

\section{Reference}

[1] Topp SK, Rosenfeldt V, Vestergaard H, Christiansen CB, Von Linstow ML. Clinical characteristics and laboratory findings in Danish children hospitalized with primary Epstein-Barr virus infection. Infectious Diseases, 2015;47(12):908-914.

[2] Taylor GS, Long HM, Brooks JM, Rickinson AB, Hislop AD. The immunology of Epstein-Barr virusinduced disease. The Immunology of Epstein-Barr Virus-Induced Disease. Annu. Rev. Immunol. 2015; $33: 787-821$.

[3] Cohen JI, Iwatsuki K, Ko YH, Kimura H, Manoli I, Ohshima K, Pittaluga S, Quintanilla-Martinez L, Jaffe ES. Epstein-Barr virus NK and T cell lymphoproliferative disease: report of a 2018 international meeting. Leukemia Lymphoma,2020 Apr;61(4):808-819.

[4] He HL, Wang MC, Huang WT. Infectious mononucleosis mimicking malignant T-cell lymphoma in the nasopharynx: a case report and review of the literature. Int J Clin Exp Pathol . 2013;6(1):105-109. 
[5] Bahethi R, Gray M, Salib C, Likhterov I. Lymphoma Mimicking Chronic Active Epstein-Barr Virus: A Case Report [published online ahead of print, 2020 Apr 29]. Head Neck Pathol. 2020.

[6] AbuSalah MAH, Gan SH, Al-Hatamleh MAl, Irekeola AA, Shueb RH, Yean Yean C. Recent Advances in Diagnostic Approaches for Epstein- Barr Virus. Pathogens.2020 Mar;9(3):226.

[7] Ciccarese G, Trave I, Herzum A, Parodi A, Drago F. Dermatological manifestations of Epstein-Barr virus systemic infection: a case report and literature review. International Journal of Dermatology. 2020 Apr 28.

[8] Christian Münz. Immune Control and Vaccination Against the Epstein-Barr Virus in Humanized Mice. Vaccines (Basel). 2019 Dec 17;7(4):217.

[9] Chen YZ, Zhou XG, Jin Y, Zheng YY, Chen G, Shi Y. Study of Clinical and Morphological Features, Immunophenotype and Epstein-Bar Virus Infection in Situ of Infectious Mononucleosis. Chin J Pathol,July 2008;37(7):440-444.

[10] Fischer E, Delibrias C, Kazatchkine MD. Expression of CR2 (the C3dg/EBV receptor, CD21) on normal human peripheral blood T lymphocytes. J Immunol.1991;146(3):865-9

\section{Figures}

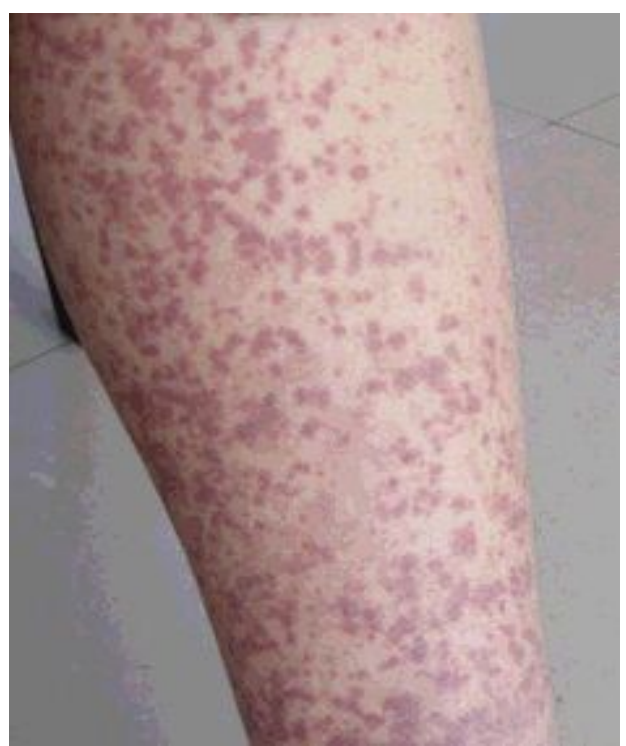

\section{Figure 1}

photograph of the right leg ecchymosis 


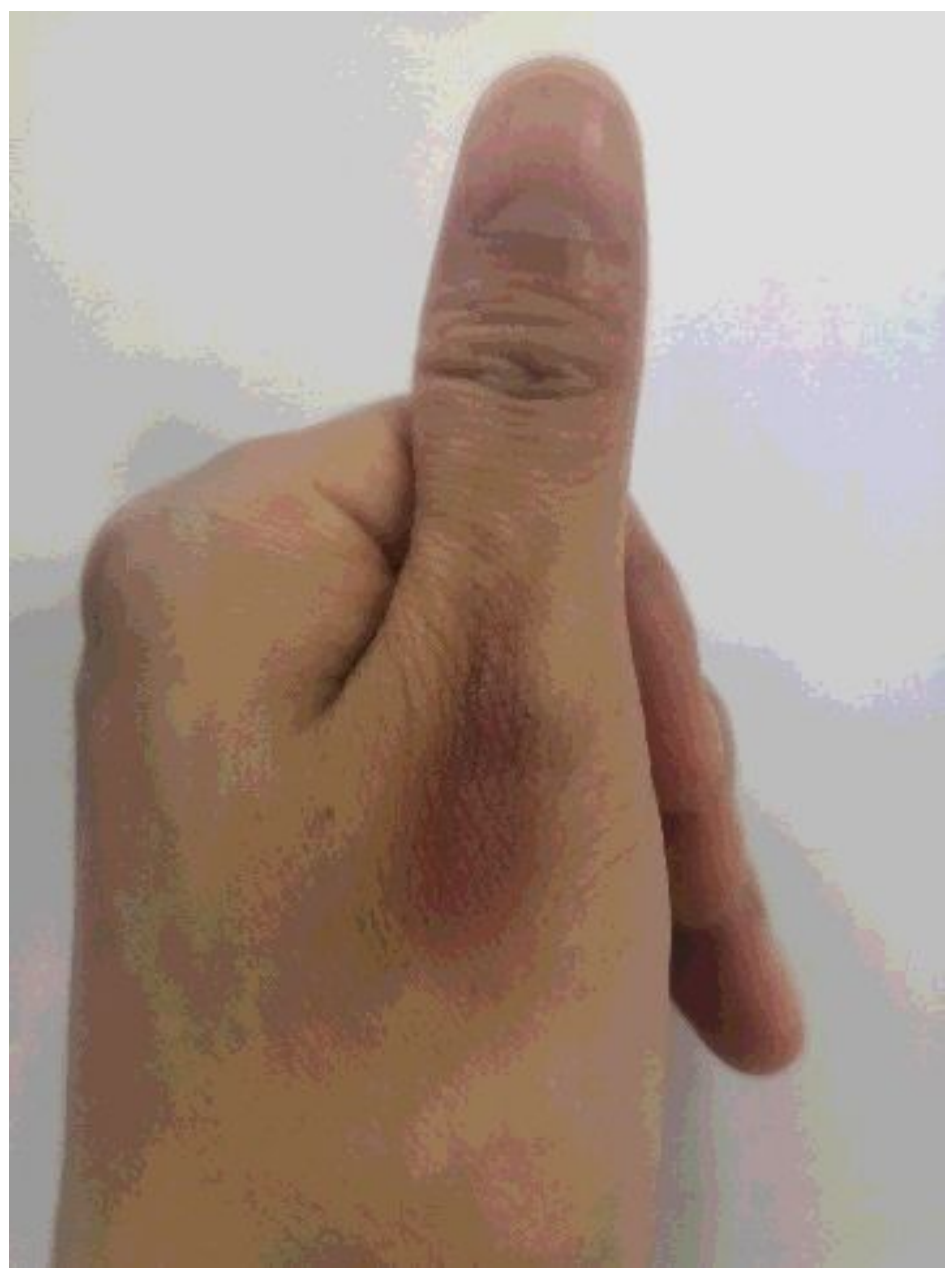

Figure 2

Photograph of petechiae on the hand 

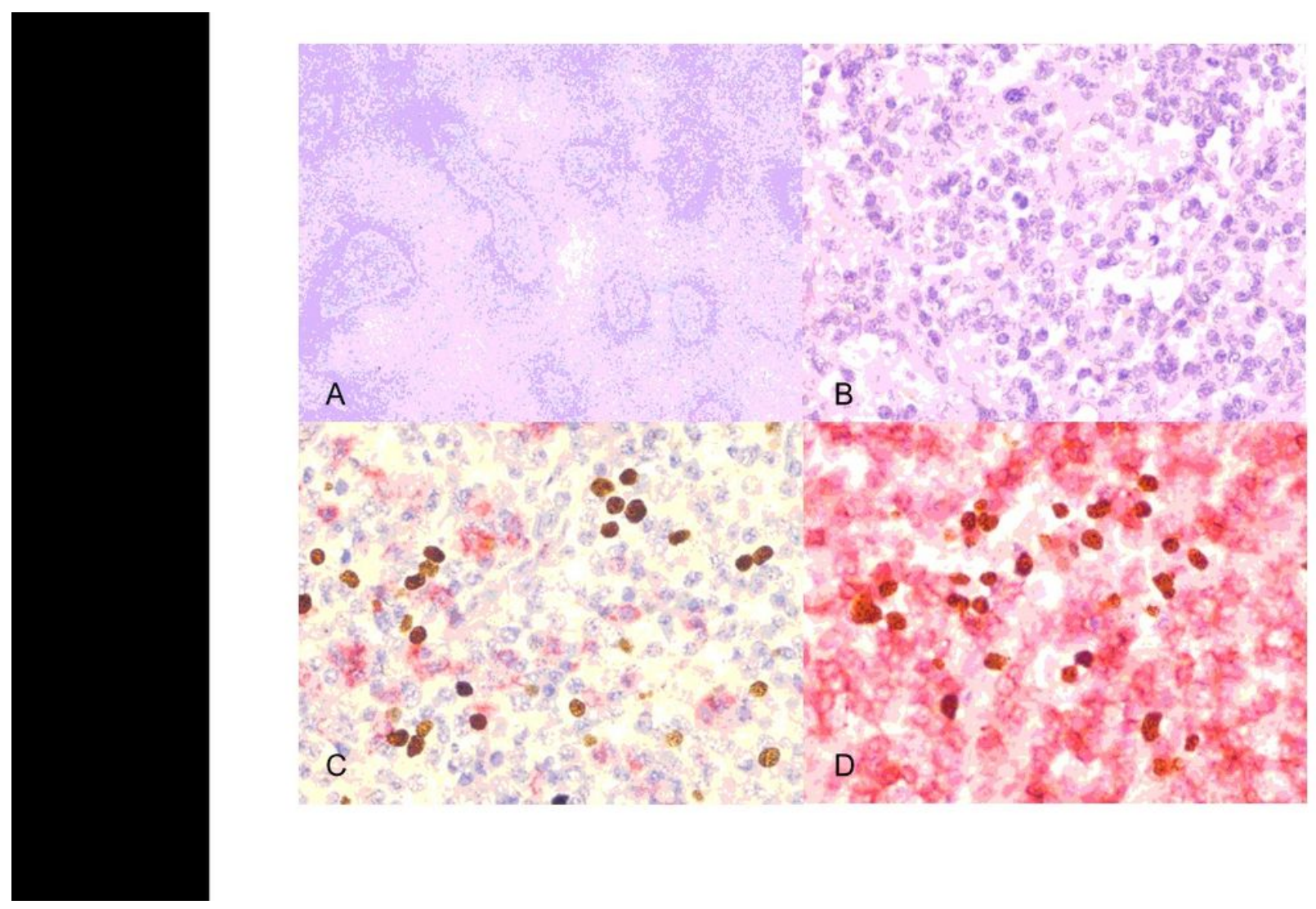

\section{Figure 3}

A few follicular germinal centers were enlarged, irregular in shape $(\times 100)$. B. Most of them had small to medium-sized nuclei, and there were also some immunoblast-like cells with cytologic atypia ( $\times 400)$. C. Most of the EBER-positive cells (brown) were actually atypical T lymphocytes without expression of CD20 (red) (×400). D. EBER-positive T cells (brown) were immunostained positive for CD8 (red) $(\times 400)$. 